\title{
Obstetric Fistula in 2015 and Beyond
}

Arrowsmith S

Medical and Programs Director, Fistula Foundation, CA, USA.

Received: November 12, 2014 ; Accepted: January 05, 2015

It seems difficult for me to believe, but I first repaired an obstetric fistula in early January 1987. At that time, the landscape of the fistula world was remarkably different. Fistula effort was confined to a very few geographic areas, each of which were completely dominated by the spirit and energy of the founder of a fistula center. The list of leading surgeons contains names familiar to fewer and fewer active fistula care providers: Drs. Ann Ward, John Lawson, and Una Lister in Nigeria were all in the late prime of their lives; in the north of Nigeria, a leprosy surgeon was just getting started in fistula repair at a new center near Katsina: the founder being Dr. Kees Waaldiijk. In eastern Africa, Dr. Abbo Hassan Abbo was dominant in Sudan, the Hamlins in Ethiopia, and an odd band of travelling surgeons, including the late Dr. John Kelly, Dr. Brian Hancock, and Dr. Tom Raassen, were establishing themselves across the region. Also quite active, but completely unheralded were a cadre of non-Western surgeons just beginning long careers in fistula repair: Drs. Mulu Muleta and Ambaye w/ Michael in Ethiopia, Dr. Kalilou Ouattara in Mali, Dr. Serigne Gueye in Senegal, Dr. Khisa Wakasiaka in Kenya, Dr. Ojengbede Akanbi in Ibadan, Nigeria, and Dr. Jonathan Karshima in Jos. Meanwhile, Dr. Kundu Yangzom was quietly establishing a tradition of quality fistula care in Nepal. Of course, this listing is far from exhaustive.

Because of the huge scale of the fistula problem and all of the overwork than ensued, the isolation of these individuals from one another, difficulty in travelling between fistula endemic areas, lack of the easy communication we enjoy today via e-mail and social media, very few of these individuals had any idea of what the others were doing, how they approached fistula repair, what supportive social and preventive programs they had in place. Everyone was inventing the wheel in isolation.

Fast-forward 28 years, and the situation is

\section{CORRESPONDENCE}

Dr Steven Arrowsmith

Consultant Urologist \& Fistula Surgeon, Fistula Foundation, USA.

Email: steven@fistulafoundation.org

Phone: +1-866-756-3700 unimaginably different. The Global Fistula Map ${ }^{1}$ now lists fully 152 centers offering fistula care. Needs in areas other than Africa have been identified and are being addressed as there are now active centers in countries like Pakistan, Afghanistan, Nepal, and Bangladesh. We have a professional society for fistula surgeons, an internationally sanctioned training curriculum, and resources from an ever-growing number of governmental and non-governmental sources. The media have awoken to the fistula issue, and the thing that so many of us referred to as the "hidden epidemic" is now thoroughly out in the open. National surgeons have begun to receive their due of international recognition and lead most of the organized international efforts against fistula. Fistula survivors also have a voice, as they are being asked to provide wisdom and perspective to programmatic strategy (such as Kenya's Sarah Omega ${ }^{2}$ of the Fistula Foundation, whom I can proudly claim as one of my bosses). In 2015, the results of the very first multicenter, prospective, randomized clinical trial will be published in a major medical journal, ${ }^{3}$ marking a new era of transcontinental cooperation and established the developing world as a place where quality clinical research can and should be done.

But in $\mathbf{2 0 1 5}$ we also face challenges that were not imaginable in 1987: First to mind is the issue of security. In 1987, there was no Boko Haram, no ISIS, no Al Shabab, AQIM, Ansaru, Taliban, or any other organized terrorist organization active in places where we fistula surgeons try to work. Add chronic conflict in Sudan and South Sudan, Afghanistan, Somalia, the DRC, Yemen, Central African Republic, among others, and there is barely a spot that one can point to in the fistula world and say with confidence that the area was "safe". Future planning must take risks of kidnapping or violent attack into consideration, both in terms of prevention and planning should such a thing happen. How does one decide when "hot" is too "hot"? If we back away from a certain area because of security, how can we decide when to return? How can we remain true to our commitment to women with fistula without assuming "undue" risk? The near-death of Dr. Denis Mukwege ${ }^{4}$ in the 
DRC, and the constant exposure of others, like Dr. Sunday Lengmang in Jos, Nigeria) remind us that these risks are very real.

In 2014, a new issue exploded onto the scene with the unprecedented outbreak of the Ebola virus in West Africa. Most of us have worked in areas where Ebola, Lassa, Marburg, Dengue, resistant Malaria, and other pathogens were a nagging concern. Have we thought through a rational approach to work in areas where epidemics like this one occur? What if Lassa broke out in your post-operative ward (as it once did in mine in Nigeria)? Do you have policy in place for this possibility? Most of the fistula work in Liberia, Sierra Leone and Guinea is currently shut down. Are we prepared to rapidly and robustly resume fistula repair when the epidemic plays out? Everyone expects there to be a new "crop" of fresh fistulae resulting from the collapse of other forms of health care during this huge epidemic. Let's be ready to go, and show the world that our commitment to the poor is not diminished, even when dangerous, hideous things like this outbreak happen.

A huge "thaw" in the isolationist past of fistula centers has begun, and it is our challenge to keep this movement alive. With the International Society of Obstetric Fistula Surgeons ${ }^{5}$, the International Obstetric Fistula Working Group ${ }^{6}$ of the UNFPA, the collaborative training effort of $\mathrm{FIGO}^{7}$ there are more and more opportunities for us to band and work together. Many countries now have a Fistula Task Force or Providers Group sponsored by the local Ministry of Health. My employers, the Fistula Foundation, have begun asking our funded sites in areas of geographic proximity to band together and to benefit from the collective wisdom, resourcefulness, and spirit of other provider working in each area. This is now reality in Nepal and in Kenya, and we hope to rapidly expand to other areas. EngenderHealth has made similar efforts at "community building" among their funded sites. We are stronger together than we are apart. Finally, there is a last challenge. Recent attempts to accurately define the incidence and prevalence of fistula based on real-world data have produced estimates significantly lower than the estimates of the past. Many centers seem to be working harder and harder to identify and assist new fistula clients. Some have begun to wonder that perhaps we have finished with the fistula problem and need to refocus our efforts and resources on other conditions impacting the quality of life of women in the developing world. My work takes me to fistula centers all over the world, and it is apparent that while some centers are working hard to find clients, others are seeing increasing numbers. The number of iatrogenic fistulae $e^{8}$ seems to be on the rise. Are our new relationships strong enough to include an approach of professional accountability to deal with this issue? We have only just begun to explore effective and rational strategies for client recruitment.

As yet we don't know if women are staying away from us because we treat them badly, whether they stay away from irrational fear, or whether they truly no longer exist. Before we declare victory over the fistula problem, we should wait for the strong data that we have always lacked. New approaches to defining incidence and prevalence of fistula are being developed using novel statistical modeling techniques. Let's give new studies a chance to shed further light on the issue. The attention focused on fistula has been far too hard-won to give it up prematurely. It is a great pleasure to submit this editorial to a Nepali publication, knowing that the women of Nepal are in good hands with a robust cadre of committed fistula surgeons now well-united in a national treatment network. All the best in 2015 as we fight together to end fistula!

\section{REFERENCES}

1. Global Fistula Map. (Cited 2014 December 29). Available from http://www.globalfistulamap.org/

2. Sarah Omega Kidangasi | Fistula Foundation. (Cited 2014 December 21). Available from http://www.fistulafoundation. org/team-members/sarah-omega-kidangasi/

3. Barone MA, Frajzyngier V, Arrowsmith S, Ruminjo J, Seuc A, Landry E, et al. Non-inferiority of short-term urethral catheterization following fistula repair surgery: study protocol for a randomized controlled trial. BMC Womens Health. 2012;12: 5 .

4. An Attack on One of My Heroes, Dr. Denis Mukwege -
NYTimes.com. (Cited 2014 December 29). Available from http://kristof.blogs.nytimes.com/2012/10/25/an-attack-onone-of-my-heroes-dr-denis-mukwege/

5. International Society of Obstetric Fistula Surgeons. (Cited 2014 December 29). Available from http://www.isofs.org/

6. News. (Cited 2014 December 29). Available from http://www. endfistula.org/public/pid/7441?feedEntryId=33084

7. Fistula Training Initiative | FIGO. (Cited 2014 December 29). Available from http://www.figo.org/fistula-training-initiative

8. RaassenTJ, Ngongo CJ, Mahendeka MM. Iatrogenic genitourinary fistula: an 18-year retrospective review of 805 injuries. Int Urogynecology J. 2014; 25(12):1699-706.. 